\title{
A concept of education in sustainable electronic design
}

\author{
V. B. Litovski, J. Milojković \& S. Jovanović \\ Faculty of Electronic Engineering, \\ University of Niš, Serbia and Montenegro
}

\section{Abstract}

A postgraduate curriculum on sustainable electronic design is briefly described. That is, to our knowledge, the only postgraduate curriculum on sustainable electronic design in South-East Europe. The motivation of this new educational effort comes from the fact that longer tradition in electronic production exists in the local region and, in the same time, long tradition in higher education in electronics exists.

There is no general awareness on the interrelation of electronic-product's life cycle (e.g. electronic production and electronic waste management) and the environment in the local communities. The main goal of this curriculum is to establish this awareness, to emphasize the role of the electronic designer in the life cycle of an electronic product, and to introduce sustainability-aware design methods. Of course, special attention is paid to end of life and especially to collection and management of electronic waist.

After the overview of the curriculum, contents of the subjects will be listed. Every content will be accompanied by some comments trying to stress some specifics of the subject, some specific goals to be achieved, or some characteristic data or method to be stressed. These are tailored for graduate electronic engineers that are expected to enter the field of sustainable design and management of the end of life of electronic products.

Part of our published research and results that are available for this curriculum will be described too. It is related mostly to information infrastructure necessary for implementation of sustainability concepts.

Keywords: sustainable electronic design, curriculum, postgraduate studies, ecological education of electronic engineers. 


\section{Introduction}

The production of electrical and electronic equipment is one of the fastest growing domains of manufacturing industry in the Western world [1]. Electronics as a human activity becomes more and more influential. There is hardly any part of life where electrical and electronic equipment are not used. The number and weight of electronic components and equipment in use becomes so high that makes electronics comparable with other much "heavier" industries. In the year of 1988 the amount of electronic equipment reaching end-of-life measures 6 million tones and is expected to double in 2010 [1]. This means that about $20 \%$ of the municipal waste stream will be related to WEEE (Waste Electrical and Electronic Equipment).

In addition, the growth of the production of electronic equipment is directly related to the rise of use of virgin materials giving no opportunity to the nature to regenerate this kind of resource. This is especially related to rare elements being used in modern electronic components.

Finally, electronic equipment is using energy for its work. The amount of energy spent by electronic appliances both active and stand-by is enormous and any optimisation leads to significant savings. This is why the electronic engineers and especially electronic designers are to accept that they are playing an exceptionally important role in the world economy and the eco-system. Slowly but surely they become part of the most influential people in the world. This is why regular education of sustainable electronic design becomes more and more important.

In this paper we will try to give an overview of the very first curriculum for postgraduate studies of sustainable electronic design in our country. It started in the year 2002. two main orientations are expected to be given. One is related to the design of electronic components, devices and equipment, while the other is expected to prepare electronic engineers to develop subsystems within the collective social effort for sustainable development. The specifics of the sustainability of electronic design are mainly thought based on publications having as a subtitle synonyms of "green book" such as [2-7].

\section{Overview of the curriculum}

It is a two years curriculum where students are though in six subject, three per year. The subjects are listed in table 1. Number one and two are used at the beginning of the subject code (column 1) to denote first and second year of studies, respectively. Two of the subjects are compulsory while students may choose among the rest according their personal interest. Small projects are part of the examining process in any subject and an MS thesis compulsory, too. At least, two publications of papers, the content being related to the projects or the MS thesis, are expected from every student.

The compulsory subjects noted by the letter A in column one of table 1 are introductory in both general subject of sustainable development, and specific relation of electronics to the sustainable development. 
The rest (marked by B) of the subject may be combined in many ways. For example, a combination containing the subjects: 1.SD.03B, 2.SD.06B, 2.SD.07B, and 2.SD.10B should prepare an expert, in the electronic design team, who may be responsible for the aspect of sustainability of the whole project.

Table 1: $\quad$ The curriculum.

\begin{tabular}{||l|l||}
\hline \hline CODE & SUBJECT \\
\hline 1.SD.01A & Sustainable development \\
\hline 1.SD.02A & Sustainable electronic design \\
\hline 1.SD.03B & Electronic circuit design \\
\hline 1.SD.04B & Electronic measurement and data acquisition systems \\
\hline 2.SD.05B & Method of standardization and standards of sustainable design \\
\hline 2.SD.06B & Physics and technology of electronic circuits and systems \\
\hline 2.SD.07B & Simulation and optimisation of electronic circuits and systems \\
\hline 2.SD.08B & End-of-life management \\
\hline 2.SD.09B & Ecological information systems for monitoring and control \\
\hline 2.SD.10B & Methods and tools of sustainable design \\
\hline
\end{tabular}

In the next the contents of the subjects will be listed together with some comments stressing some specific aspects of the teaching and/or relation to other general subjects or subjects within this curriculum.

\section{Contents and comments}

The contents listed below are expected to be the ones that, we consider, are necessary for the student at the moment. We intend to monitor the developments in any subject and to accommodate according to any important change. We are aware, of course, that any teacher will give a specific taste to the subject he or she is teaching.

\subsection{SD.01A Sustainable development}

Content: Human-nature interaction. Pollution of natural resources such as water, air, and soil. Energy and ecology. Electronics and Ecology. Economical aspects. Relation of the overpopulation, over-consumption etc. to the ecological principles. Ecological problems in cities. Concepts of sustainable design. International organizations dealing with sustainable development. The electronic designer and the eco-tasks. Problems of ecological education of electronic engineers.

Comment:

The point here is to establish awareness that electronics has relation with sustainability at a global level. Examples of how electronics is influencing pollution are given exemplifying all aspects: material (frequently poisonous) and energy consumption, electromagnetic radiation, and air, water, and soil pollution. 


\subsection{SD.02A sustainable electronic design}

Content: The life-cycle. Sustainable pricing of products. Exploitation phase. End-of-life. Reuse. Dismantling. Disposal. Take-back. Concepts of sustainable design. Design phase. The role of the designer. Effects of sustainable design. Methods of sustainable design. Sustainable design of electronic products.

Comments:

-Design for dismantling and similar aspects is stressed here.

-In addition, design methods are discussed that allow for monitoring of the life cycle of critical parts within an electronic equipment so enabling decision making about its reuse at the end-of-life of the equipment.

-Special attention is paid to maintenance. Namely, in the first life of the product maintenance means making it longer (among other) by use of spear parts. These spear parts, however, may be taken from a used system so prolonging its second life. This becomes especially important for maintenance of industrial facilities that, when operating, perform well even if old electronic technology is applied.

\subsection{SD.03B Electronic circuit design}

Content: Electronic circuits CAD. Systems for CAD. Hardware description languages. Application on nonelectrical systems design. Integrated circuits design. Technology design, simulations, physical design, symbolic topology design, DRC, compaction. Techniques for ASIC design. System and systematic design aspects. IC testing. Specifics of printed circuit board design.

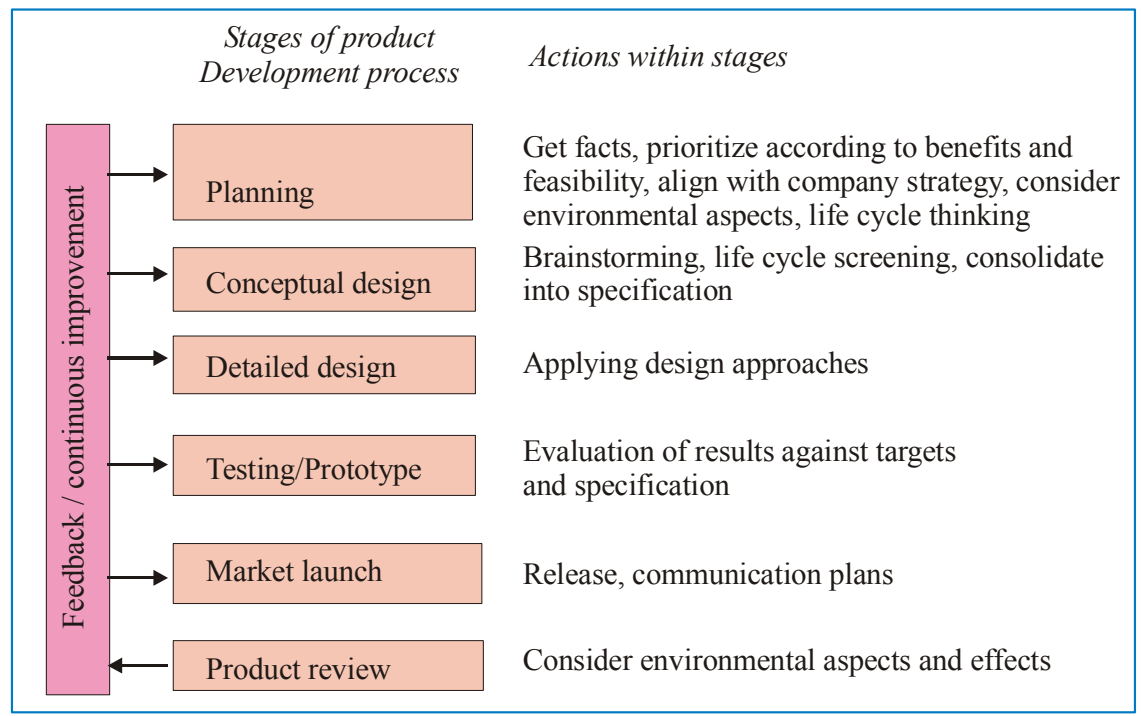

Figure 1: Generic model of integrating environmental aspects into product development process. 
Comments:

-Fig. 1 represents the generic model advocated for the integration of environmental aspects into the product development process [8]. This, of course, should be considered as one among many concepts (such as [3]) and should not exclude any further improvement.

-Choice of digital alternatives is recommended while electronic circuit synthesis is considered.

-Bare board design is twofold optimisation problem. First, one should think on placement and routing on the board what is usual electronic design problem. The goals here is to achieve minimum area, short connections (high frequencies), low voltage drops etc. On the other hand, having in mind the production process and waste generated during production, one is supposed to optimise: the copper fraction on a single layer, the number of boards per panel, and the total number of signal layers [9].

\subsection{SD.04B Electronic measurement and data acquisition systems}

Content: Measurement of physical, chemical and biological quantities. A/D and $\mathrm{D} / \mathrm{A}$ conversion. Analogue and digital processing of measured data. Advanced digital signal processing. Structure of a data acquisition system. Communication interfaces and standards.

Comment:

-Among environmentally important quantities to be measured one should recognize: temperature, humidity, wind velocity, toxic chemical $\left(\mathrm{CO}_{2}, \mathrm{SO}_{2}\right.$ etc.) and biological agents in air, water, and soil, personal contamination vibration, noise etc. Special attention is paid to detection/diagnosis of harmful chemical and biological agents including explosives, nerve gases, mycotoxins, viruses, pathogenic bacteria and biological toxins.

\subsection{SD.05B Method of standardization and standards of sustainable design}

Content: Complexity of the standardization process. Procedures for standardization. Standardization organizations. Access to standards. Standards related to industrial environment. European standardization bodies. Home standardization institutions. Anti-trust low. Concepts and contents of ISO14000.

Comments:

-When speaking on ISO 14000, a short overview of ISO9000 is thought and its relation to ISO14000 is stresses,

-Environmental management system (14001) gives specification with guidance for use,

-Guidelines for environmental auditing (14010). Gives general principles of environmental auditing,

-General principles of environmental labelling, (14020)

-Environmental management $(1404 x, x=0, \ldots, 9)$ includes principle and guidelines for LCA,

-Terms and definitions (14050), 
-Guide for inclusion of environmental aspects in product standard (14060), -The important thing to introduce, however, is that every organization that wants to adopt the ISO 14000 standards is supposed to obey not only national but international regulations, too. In addition when the certificate is issued the organization will be expected to have an effective system of internal management that is accommodated to the application of the ISO 14000.

\subsection{SD.06B Physics and technology of electronic circuits and systems}

Content: Materials used in electronic production. Process modelling. Reliability. Yield. Health hazard assessment. Reuse of materials and components. Passive and active discrete electronic component technologies. Integrated circuits. Thick film technology. Bipolar technologies. MOS technologies. PCBs. Assemblies.

Comments:

-Lists of poisonous materials and health hazards during production are introduced first.

-Theory of computation of yield reliability is related to the waste generated during production and to the prolongation of the product's life. In that sense these two categories become important criteria for sustainability evaluation of a design.

\subsection{SD.07B Simulation and optimisation of electronic circuits and systems}

Content: Electronic circuit analysis in time and frequency domain. Methods of analog optimisation. Constrained optimisation. Evolutionary algorithms for optimisation. Deterministic and statistical tolerance analysis and design. Power and delay estimation methods. Logic simulation. Discrete event simulation. Test pattern generation. Basics of diagnostics.

Table 2: $\quad$ Logic versus discrete event simulation.

\begin{tabular}{||c|c||}
\hline LOGIC SIMULATION & DISCRETE-EVENT SIMULATION \\
\hline deterministic event generation & stochastic event generation \\
\hline logic models & analog and/or logic models \\
\hline deterministic delay models & stochastic delay models \\
\hline \multicolumn{2}{|c||}{ next event algorithm } \\
\hline \multicolumn{2}{|c||}{ selective trace algorithm } \\
\hline
\end{tabular}

Comment:

-As an illustration of how sustainability may be related to ordinary knowledge of electronic design a comparison is given in table 2 relating logic and discrete event simulation. The former is used for design verification and test signal evaluation in logic design, while the letter is supposed to predict the timing in the life-cycle of a product [10]. 


\subsection{SD.08B End-of-life management}

Content: Resell, upgrade, and recycle options. Evaluating the environmental effectiveness of reselling, upgrading and recycling. Re-manufacturing. Product returns systems. Logistics. Producer responsibility. Recycling processes and technologies. Demanufacturing. Disposal.

Comment:

-Awareness of the amount of electronic waste is one of the important aspects of teaching this subject.

-Establishment of an effective product return system accommodated to the way of functioning the society both locally and on the state level is of prime importance.

-Specific recycling processes such as $\mathrm{PCB}$ recycling or monitor recycling are studied.

-Concepts of (computer) upgrading are studied, too.

\subsection{SD.09B Ecological information systems for monitoring and control}

Content: Eco-parameters that may be measured. Concepts of conversion of natural quantities into electrical ones. Environmental transducers. Eco-data acquisition at the level of industrial objects, at the level of municipality, and at the level of a country. Ecological information systems. Monitoring, statistical evaluation, and control of ecological parameters. Avoiding hazardous situation by monitoring ecological parameters.

Comment:

-This is a subject that is most convenient for practical evaluation of projects. Namely the students are directed to different university partners having their own, more or less complete, information systems related to sustainability.

\subsection{SD.10B Methods and tools of sustainable design}

Content: Classification of the procedures for sustainable design. Full Life Cycle Analysis (LCA). Life cycle costing (LCC). Partial LCA: Ecoindicator, Product improvement method (PIM), Method of assessment of ecological data. Optimisation of logistic systems. Integrated system for eco documentation. Databases for sustainable design.

Comments:

-We suggest the classification done by Digital Equipment Corporation and the MIT Program on Technology, Business and Environment to be accepted. They classify DfE tools according to three primary attributes. First, a tool's applicability to product development stages will indicate whether a tool may be used for simply establishing project goals or actually developing detailed designs. Second, its degree of applicability to product life cycle stages determines how appropriately life-cycle stages are applied to a product's design and how many life cycle stages the tool supports. Finally, a tool's degree of decision support accounts for the type of data output generated (inventory tools 
generate raw data, impact tools aggregate the data, and improvement tools generate design alternatives that minimize environmental impact [11].

-The standardized $[12,13]$. LCA is a complex tool for assessment of the environmental impact during the whole life-cycle of the product. Main difficulties in the implementation of LCA are related to some system modelling due to the data uncertainty for product's end of life because it is nearly impossible to collect real data on end-of-life processing at the design stage. End-of-life effects are difficult to anticipate for complex products with long lifetimes.

-The detailed study being time consuming, expensive and, in some cases difficult to realize, one use simplified methods. These methods mainly take into account only part of the whole life-cycle and consider only some impacts to the environment.

\section{Toward an integrated life-cycle design tool}

Within our research, partly by help of students but mostly in collaboration with some local small high-tech enterprises, we started a development of a complex informational infrastructure that is supposed to be used as a support to sustainable product design [14]. It is expected to be used by students preparing projects in most of the subjects described, and as a production company resource, as well.

Here the tasks, the goals, concepts and preliminary result will be described for such an attempt. The objectives were to build an integrated information system that will be open both vertically and horizontally. It will include XML Web Services and software tools for documenting services together with software tools for life-cycle evaluation services. The system under development is depicted in fig. 2. A front-end substructure was designed in order to enable communication between the project manager and production, customers, market partners and research and development departments. Several data-bases (Db) were to be designed and created, such as material, components, modules, products technologies (production, recycling) standards, legislation, professional and scientific literature, life cycle, important research institutions, and similar. The middle layer of the system consists of a set of development tools (CAD/CAM/CAE, Products and Technology Documenting Tools, Life Cycle and Cost/Benefit Evaluation) and SW tools for working with Databases. The system is intended to be organized as company products development system, which can be distributed as multi location system, or it can be organized as service for products development, which could be used on rental base.

Among other, SW tools for Life cycle and Cost/Benefit will be introduced in order to provide life-cycle simulation and Cost/Benefit evaluation as well as to define recycling logistics and technology. This part of the system has a subsystem to document all this, based on solution already described earlier. To allow Life cycle data acquisition separate $\mathrm{B}^{2}$ service and $\mathrm{B}-\mathrm{C}$ service will be provided, so that product sales and service network as well as customers can submit appropriate data. 
Project management system is going to be built to provide tool for product design teams management. Messaging within the system will be done using standard products.

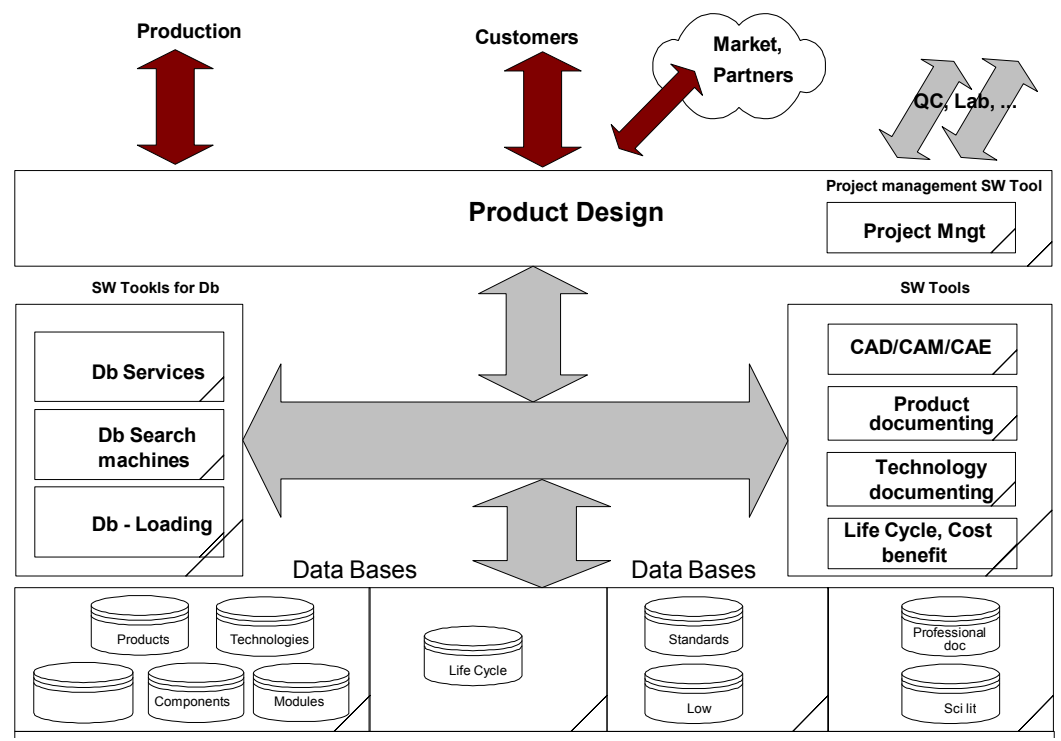

Figure 2: $\quad$ Structure of an information system supporting sustainable design.

Integrated Information Infrastructure for Sustainable Product Design System described here can be implemented as a company resource or as service resource available for public use or to be used as commercial service.

When used as company resource, based on described functionality it can serve development activities on the company Intranet. Its functionality can be extended to Extranet to allow business partners to be included in. Db-s could be both centralized and distributed, but to the users they will be exposed as unique $\mathrm{Db}$-s, provided that they will be loaded according to the procedures which will be built as admin tools. Built in XML Web services will provide efficient.

The system can be organized and used as Internet service resource, either public or commercial one. For this purpose administration of the system is customized to allow security administration for users of the system.

\section{Conclusion}

A postgraduate MS level curriculum is described that started in the year 2002 at the Faculty of Electronic Engineering, University of Nis, Serbia and Montenegro. Contents of subjects are given together with comments related to some aspects of the realization of the educational process. Some research results 
are mentioned that are, among other, intended to become available to students in the future.

\section{References}

[1] Appelbaum, A., Europe Cracks Down on E-Waste, IEEE Spectrum, 39(5), pp. 46-51, 2002.

[2] Eureka E! 2009, Strategic Comprehensive Approach for electronics REcycling and Re-use, SCARE, Green Book, International CARE "VISION 2000" Office, Wiener Neustadt, 2000.

[3] Ferrendier, S. et all., Environmentally improved product design case studies of the European electrical and electronics industry, ECOLIFE Thematic Network, Eco-design subgroup, 2002.

[4] Goldberg, L., Green electronics/Green bottom line, Newnes, Boston, 1999.

[5] Milojkovic, J., and Litovski V., Eco-design in Electronics - The State of the Art, Facta Universitatis, Series: Working and living Environment Protection, University of Nis, 2(2), pp. 87-100, 2002.

[6] Wimmer, W., Zust, R., \& Lee, K., Ecodesign Implementation, Springer, The Netherlands, 2004.

[7] Kuehr, R., \& Williams, E., Computers and the Environment, Kluwer Academic Publishers, Dordrecht/Boston/London, 2004.

[8] Stevels, A., Ecodesign for competitive advantage, Proc. of the 1st regional conference for manufacturing companies: Eco-design for Competitive Advantage, Inst. of Mechanical Engineers, London, pp. 1.1$1.5,2001$.

[9] Balakrishnan, S., and Pecht, M., Placement and routing of electronic modules, Marcel Dekker, New York, pp. 95-96, 1995.

[10] Litovski, V, and Zwolinski, M., VLSI circuit simulation and optimisation, Chapma and Hall, London, 1997.

[11] Roll, M., and Ehrenfeld, J., Implementing design for environment: $A$ primer, Digital Equipment Corporation, Maynard, MA, pp. 15-16, 1997.

[12] ISO 14040, Environmental Management - Life Cycle Assessment Principles and Framework, Berlin, Deuth, 1997.

[13] Weidema, B.P. Improving the performance of LCA, Proc. of the 2. International Conference on EcoBalance, Tsukuba, pp. 247-252, 1996.

[14] Jovanovic, S., Milojkovic, J., and Litovski, V, Information Infrastructure for Sustainable Product Design System, Proceedings of the Symposium: $e$ ecological manufacturing, Berlin, pp. 75-77, 2003. 